\title{
Environment of titanium and aluminum in a magnesium alumino-silicate glass
}

\author{
Marie Guignard $^{1}$, Laurent Cormier ${ }^{1,5}$, Valérie Montouillout ${ }^{2,3}$, \\ Nicolas Menguy ${ }^{1}$, Dominique Massiot ${ }^{2,3}$ and Alex C Hannon ${ }^{4}$ \\ ${ }^{1}$ Institut de Minéralogie et de Physique des Milieux Condensés, CNRS UMR 7590, \\ Université Pierre et Marie Curie, Université Paris Diderot, IPGP, 140 rue de Lourmel, \\ F-75015 Paris, France \\ ${ }^{2}$ Conditions Extrêmes et Matériaux: Haute Température et Irradiation CEMHTI, CNRS UPR \\ 3079, 1D Avenue de la Recherche Scientifique, F-45071 Orléans Cedex 2, France \\ ${ }^{3}$ Faculté des Sciences, Université d'Orléans, Avenue du Parc Floral, BP 6749, \\ F-45067 Orléans Cedex 2, France \\ ${ }^{4}$ ISIS Facility, CCLRC Rutherford Appleton Laboratory, Chilton, Didcot, Oxon OX11 OQX, \\ UK \\ E-mail: cormier@impmc.jussieu.fr
}

Received 25 May 2009, in final form 16 July 2009

Published 17 August 2009

Online at stacks.iop.org/JPhysCM/21/375107

\begin{abstract}
The structure of the glass $2 \mathrm{MgO}-2 \mathrm{Al}_{2} \mathrm{O}_{3}-5 \mathrm{SiO}_{2}-\mathrm{TiO}_{2}$ was investigated using neutron diffraction with isotopic substitution. Reverse Monte Carlo (RMC) modeling was used to reproduce experimental structure factors derived from diffraction experiments. The local environment of titanium atoms was determined and it corresponds to an average of $5.4 \pm 0.2$ oxygen atoms at a mean distance of $1.86 \pm 0.02 \AA$. This coordination number agrees with the predominance of fivefold coordination, with the coexistence of four- and sixfold coordination in similar amounts. ${ }^{27} \mathrm{Al}$ nuclear magnetic resonance (NMR) results revealed that the proportion of highly coordinated aluminum atoms in this titanium-bearing glass was higher than in the titanium-free sample. RMC modeling was used to interpret the structural role of these ${ }^{[5]} \mathrm{Al}$ species and we show a trend for preferential bonding between ${ }^{[5]} \mathrm{Al}$ and $\mathrm{Ti}$ atoms. This favored linkage is important to understand the role of titanium dioxide as a nucleating agent in inorganic glass-ceramics fabrication.
\end{abstract}

\section{Introduction}

Among the important questions in physics is the reorganization of structure from an ordered to a disordered material. In this context, the nucleation and crystallization of a glass is still a debated issue since classical nucleation theory fails to give a quantitative description. Such discrepancies come in part from the lack of structural investigations at the atomic scale [1]. The nucleation process is often improved by the addition of nucleating agents in glasses, which promote bulk nucleation and increase nucleation kinetics. Titanium is considered as one of the most efficient nucleating agents for the production of silicate glass-ceramics [2]. However, the titanium structural environment in glass compositions relevant to industrial applications and its influence on the overall glass

5 Author to whom any correspondence should be addressed. structure have been poorly characterized. The objectives of this study are thus to characterize in detail the glass structure and especially the Ti environment in order to elucidate possible relationships between structure and nucleation.

In silicate glasses, $\mathrm{Ti}$ atoms exist in a variety of structural states, showing remarkable behavior as an intermediate between well-defined network-forming and network-modifying cations. The environment of titanium has been mainly investigated in the $\mathrm{TiO}_{2}-\mathrm{SiO}_{2}$ binary system [3-5] and Ti-bearing alkali or alkaline-earth silicate glasses [6-12]. All these studies show that titanium atoms are present in the glass with multiple coordination numbers from four to six.

$\mathrm{TiO}_{2}-\mathrm{SiO}_{2}$ binary glasses have been mainly investigated using $\mathrm{Ti} \mathrm{K}$ - and L-edges and $\mathrm{O}$ K-edge x-ray absorption spectroscopy (XAS) $[4,12,13]$. At low $\mathrm{TiO}_{2}$ content (up to $\left.6 \mathrm{~mol} \% \mathrm{TiO}_{2}\right), \mathrm{TiO}_{2}-\mathrm{SiO}_{2}$ glasses contain predominantly fourfold-coordinated titanium atoms, ${ }^{[4]} \mathrm{Ti}$, and $\mathrm{Ti}$ is assumed 
to substitute for silicon in tetrahedral units. As the $\mathrm{TiO}_{2}$ content increases and exceeds $6 \mathrm{~mol} \%$, the amount of fivefoldcoordinated, ${ }^{[5]} \mathrm{Ti}$, or sixfold-coordinated, ${ }^{[6]} \mathrm{Ti}$, titanium atoms increases.

Similar behavior has been observed by XAS for alkalineearth glasses but with a higher average coordination number of Ti ranging from 4.8 to 5.8 [9, 12]. In highly polymerized networks, a significant amount of ${ }^{[4]} \mathrm{Ti}$ atoms is present, while it decreases below $10 \%$ in highly depolymerized networks. As for sixfold-coordinated titanium atoms, their presence remains minor and they are even sometimes excluded [12]. Sodium silicate glasses have a mix of ${ }^{[4]} \mathrm{Ti}$ and ${ }^{[5]} \mathrm{Ti}$ up to $14.3 \mathrm{wt} \% \mathrm{TiO}_{2}$, and then only ${ }^{[5]} \mathrm{Ti}$. Potassium silicate glasses have the same behavior with more ${ }^{[4]} \mathrm{Ti}$, indicating that large alkali cations appear to stabilize a relatively low average $\mathrm{Ti}$ coordination number compared to the smaller alkaline-earth cations $[12,14]$.

The fivefold coordination site has been unambiguously determined by neutron diffraction using Ti isotopic substitution and it corresponds to an original symmetry of a square-based pyramid $[15,16]$. Four oxygens at an average distance of $1.96 \AA$ form the base of the pyramid and one oxygen at a short distance of $1.68 \AA$ (known as a titanyl bond) is at the apex [16]. This titanyl bond is non-bridging, allowing Ti to play both a network-forming and network-modifying role in the structure. Note that a fivefold coordination geometry corresponding to a trigonal pyramid was only suggested in metamict zirconolite $\mathrm{CaZrTi}_{2} \mathrm{O}_{7}$, whose crystalline counterpart also contains this geometry [8].

The Ti environment in alumino-silicate glasses has only been studied by Ti K-edge XAS [9, 14]. Alkaline-earth alumino-silicate glasses with $5 \mathrm{~mol} \% \mathrm{TiO}_{2}$ contain both ${ }^{[4]} \mathrm{Ti}$ and ${ }^{[5]} \mathrm{Ti}\left({ }^{[5]} \mathrm{Ti} \sim 60-75 \pm 10 \%\right.$ of the total $\mathrm{Ti}$ ), while in alkali alumino-silicate glasses the presence of $\mathrm{Al}$ in the glass causes some ${ }^{[5]} \mathrm{Ti}$ to transform into ${ }^{[4]} \mathrm{Ti}$, with a maximum of about $40 \%$ of ${ }^{[4]} \mathrm{Ti}$. There is little evidence from XAS for a significant amount of ${ }^{[6]} \mathrm{Ti}$ (estimated $<20 \%$ ). The first studies on Mg-alumino-silicate glasses have been reinterpreted with the presence of major amounts of ${ }^{[5]} \mathrm{Ti}[9,17-19]$. Raman investigations suggest the formation of aluminotitanate complexes in alumino-silicate glasses, in which ${ }^{[4]} \mathrm{Ti}$ sites predominate [20].

These studies show that the titanium environment in alumino-silicate glasses has still been poorly characterized and in particular the medium-range order (3-15 $\AA$ ) remains unknown. Glasses in the $\mathrm{MgO}-\mathrm{Al}_{2} \mathrm{O}_{3}-\mathrm{SiO}_{2}$ system are the most common compositions from which low dielectric constant commercial glass-ceramics are derived [21]. The use of $\mathrm{TiO}_{2}$ as a nucleating oxide is well recognized but the titanium structural role and its spatial distribution in the initial glass is not understood. In this paper, we focus on the cordierite composition $\left(2 \mathrm{MgO}-2 \mathrm{Al}_{2} \mathrm{O}_{3}-5 \mathrm{SiO}_{2}\right)$ that has important technological applications.

As has been shown previously, neutron diffraction with isotopic substitution is a powerful method to obtain structural information around titanium atoms in amorphous materials $[15,16,22]$. In the present study, we aim to characterize the $\mathrm{Ti}$ environment and its structural influence
Table 1. Atomic composition determined by microanalyzer $\left( \pm 0.1\right.$ at. \%) and density $\left( \pm 0.005 \mathrm{~g} \mathrm{~cm}^{-3}\right)$ of the $2 \mathrm{MgO}-2 \mathrm{Al}_{2} \mathrm{O}_{3}-5 \mathrm{SiO}_{2}$ (COR) glass and the two $2 \mathrm{MgO}-2 \mathrm{Al}_{2} \mathrm{O}_{3}-5 \mathrm{SiO}_{2}-\mathrm{TiO}_{2}$ (Ti-COR) glasses.

\begin{tabular}{|c|c|c|c|c|c|c|}
\hline Glass sample & $\mathrm{Si}$ & $\mathrm{Al}$ & $\mathrm{Mg}$ & $\mathrm{Ti}$ & $\mathrm{O}$ & $\begin{array}{l}\text { Density } \\
\left(\mathrm{g} \mathrm{cm}^{-3}\right)\end{array}$ \\
\hline $2 \mathrm{MgO}-2 \mathrm{Al}_{2} \mathrm{O}_{3}-5 \mathrm{SiO}_{2}$ & 17.2 & 14.0 & 6.7 & & 62.1 & 2.620 \\
\hline $\begin{array}{l}2 \mathrm{MgO}-2 \mathrm{Al}_{2} \mathrm{O}_{3}-5 \mathrm{SiO}_{2}-\mathrm{TiO}_{2} \\
\text { ( }{ }^{46} \mathrm{Ti} \text { enriched) }\end{array}$ & 15.8 & 12.2 & 6.3 & 3.2 & 62.5 & 2.696 \\
\hline $\begin{array}{l}2 \mathrm{MgO}-2 \mathrm{Al}_{2} \mathrm{O}_{3}-5 \mathrm{SiO}_{2}-\mathrm{TiO}_{2} \\
\left({ }^{48} \mathrm{Ti} \text { enriched }\right)\end{array}$ & 16.0 & 12.3 & 5.8 & 3.2 & 62.7 & 2.682 \\
\hline
\end{tabular}

on a magnesium alumino-silicate glass using this method. Additional information was obtained using x-ray diffraction and ${ }^{27} \mathrm{Al}$ nuclear magnetic resonance (NMR). Computer modeling of the diffraction data was performed using the reverse Monte Carlo method to provide a structural model of the $2 \mathrm{MgO}-2 \mathrm{Al}_{2} \mathrm{O}_{3}-5 \mathrm{SiO}_{2}-\mathrm{TiO}_{2}$ glass. The detailed $\mathrm{Ti}$ coordination is obtained showing the existence of a mixture of ${ }^{[4]} \mathrm{Ti},{ }^{[5]} \mathrm{Ti}$ and ${ }^{[6]} \mathrm{Ti}$. The presence of $\mathrm{TiO}_{2}$ modifies the alumino-silicate network, favoring the formation of fivefoldcoordinated aluminum atoms, ${ }^{[5]} \mathrm{Al}$. The atomic model obtained by fitting the experimental data gives the spatial $\mathrm{Ti}$ distribution and shows the preferential edge-sharing bonds between $\mathrm{TiO}_{x}$ and $\mathrm{AlO}_{5}$ polyhedra, which is a structural key to understanding nucleation processes.

\section{Experimental methods}

\subsection{Sample preparation}

One glass sample with the cordierite composition $2 \mathrm{MgO}$ $2 \mathrm{Al}_{2} \mathrm{O}_{3}-5 \mathrm{SiO}_{2}$ (COR) and two glass samples with the molar chemical composition $2 \mathrm{MgO}-2 \mathrm{Al}_{2} \mathrm{O}_{3}-5 \mathrm{SiO}_{2}-\mathrm{TiO}_{2}$ (Ti-COR) were prepared by melting dried starting materials $(\mathrm{MgO}$, $\mathrm{Al}_{2} \mathrm{O}_{3}, \mathrm{SiO}_{2}$ and $\mathrm{TiO}_{2}$ ). The first sample containing titanium was enriched in ${ }^{46} \mathrm{TiO}_{2}(70.2 \%)$ and the second one with ${ }^{48} \mathrm{TiO}_{2}(97.7 \%)$. Powders were melted at $1600{ }^{\circ} \mathrm{C}$ for $1 \mathrm{~h}$ in a $\mathrm{Pt}$ crucible and quenched from high temperature by immersing the bottom of the crucible into water. The obtained glasses were ground and melted once again to ensure a good homogeneity. The compositions were determined using an electron microprobe microanalyzer (CAMECA SX50) at the Camparis Centre (Université Pierre et Marie Curie, France). The densities were determined in toluene using the Archimedes principle with an accuracy of $\pm 0.005 \mathrm{~g} \mathrm{~cm}^{-3}$. The chemical compositions of the studied glasses are reported in table 1 , as well as their densities.

The glass samples containing titanium exhibit a slight brownish color due to the reduction of some $\mathrm{Ti}^{4+}$ ions to $\mathrm{Ti}^{3+}$ ions. As trivalent titanium ions are the only ions with a free electron, we calculated their amount in the glass samples by using electron paramagnetic resonance (EPR) (Bruker), indicating less than $300 \mathrm{ppm} \mathrm{Ti}^{3+}$ ions of total titanium atoms. Transmission electron microscope images (JEOL) confirmed the absence of nanometer-size heterogeneities (crystalline or amorphous). 


\subsection{Neutron diffraction with isotopic substitution}

The neutron diffraction experiments for the two glasses containing titanium were carried out at room temperature using the General Materials Diffractometer (GEM) at ISIS (Rutherford Appleton Laboratory, UK). Approximately $5 \mathrm{~g}$ of glass powders were loaded into a cylindrical vanadium can. Data were corrected for background and container scattering, absorption, multiple scattering and inelastic effects using the GUDRUN software to obtain the structure factor $F^{N}(Q)$. The notation for the structure factors and correlation functions are explained in previous papers [23, 24].

For neutron diffraction, the total structure factors of the studied glass samples are defined as

$$
F^{N}(Q)=\sum_{i, j} c_{i} c_{j} \bar{b}_{i} \bar{b}_{j}\left[F_{i j}(Q)-1\right],
$$

where $c_{i}$ represents the atomic concentration of species $i, \bar{b}_{i}$ represents the bound coherent scattering length for species $i$ and $F_{i j}(Q)$ is the partial structure factor corresponding to the correlation between atoms $i$ and $j$. The differential correlation function $D^{N}(r)$ is obtained by Fourier transform of the total structure factor:

$$
D^{N}(r)=\frac{2}{\pi} \int_{0}^{\infty} Q F(Q) M(Q) \sin (Q r) \mathrm{d} Q,
$$

where $M(Q)$ is a modification function to limit the effects of truncation. A Lorch function was chosen as the modification function [25]. The $D^{N}(r)$ function is defined as a sum of the partial pair distribution functions (PPDFs), $g_{i j}(r)$, corresponding to the correlation between atoms $i$ and $j$ :

$$
D^{N}(r)=4 \pi r \rho_{0} \sum_{i, j} c_{i} c_{j} \bar{b}_{i} \bar{b}_{j}\left[g_{i j}(r)-1\right],
$$

where $\rho_{0}$ is the number density.

Due to the different titanium isotopic content, the Ti bound coherent scattering length is different for the two samples: $\bar{b}_{46}=2.193 \mathrm{fm}$ and $\bar{b}_{48}=-5.636 \mathrm{fm}$, according to the isotopic content of the starting $\mathrm{TiO}_{2}$ oxides. Therefore, their total structure factors, $F^{46}(Q)$ and $F^{48}(Q)$, differ by an amount $\Delta F^{\mathrm{Ti}}(Q)=F^{46}(Q)-F^{48}(Q)$. Assuming that the structure of the two glass samples is equivalent, the first difference structure factor contains only the partial structure factors involving $\mathrm{Ti}[16,26]$ :

$$
\begin{aligned}
& \Delta F^{\mathrm{Ti}}(Q)=\sum_{i \neq \mathrm{Ti}} 2 c_{i} c_{\mathrm{Ti}} \bar{b}_{i}\left(\bar{b}_{46}-\bar{b}_{48}\right)\left[F_{i \mathrm{Ti}}(Q)-1\right] \\
& \quad+c_{\mathrm{Ti}}^{2}\left(\bar{b}_{46}^{2}-\bar{b}_{48}^{2}\right)\left[F_{\mathrm{TiTi}}(Q)-1\right] .
\end{aligned}
$$

Finally, a Fourier transform gives the Ti-centered correlation function, $\Delta D^{\mathrm{Ti}}(r)$, expressed as

$$
\begin{aligned}
& \Delta D^{\mathrm{Ti}}(r)=4 \pi r \rho_{0}\left[\sum_{i \neq \mathrm{Ti}} 2 c_{i} c_{\mathrm{Ti}} \bar{b}_{i}\left(\bar{b}_{46}-\bar{b}_{48}\right)\left[g_{i \mathrm{Ti}}(r)-1\right]\right. \\
& \left.+c_{\mathrm{Ti}}^{2}\left(\bar{b}_{46}^{2}-\bar{b}_{48}^{2}\right)\left[g_{\mathrm{TiTi}}(r)-1\right]\right] .
\end{aligned}
$$

Another difference structure factor eliminating the partial structure factors involving Ti can be calculated:

$$
\Delta F^{\mathrm{noTi}}(Q)=\left(\frac{F^{46}(Q)}{\bar{b}_{46}}-\frac{F^{48}(Q)}{\bar{b}_{48}}\right)\left(\frac{1}{\bar{b}_{46}}-\frac{1}{\bar{b}_{48}}\right)^{-1} .
$$

Although $\Delta F^{\mathrm{noTi}}(Q)$ contains the contribution of $\mathrm{Ti}-\mathrm{Ti}$ correlations, these correlations are negligible due to the low Ti content in the glasses. Therefore, this difference structure factor $\Delta F^{\mathrm{noTi}}(Q)$ can be approximated as

$$
\Delta F^{\mathrm{noTi}}(Q) \approx \sum_{i, j \neq \mathrm{Ti}} c_{i} c_{j} \bar{b}_{i} \bar{b}_{j}\left[F_{i j}(Q)-1\right]
$$

Finally, the 'Ti-free' correlation function $\Delta D^{\text {noTi }}(r)$ is

$$
\Delta D^{\mathrm{noTi}}(r) \approx 4 \pi r \rho_{0} \sum_{i, j \neq \mathrm{Ti}} c_{i} c_{j} \bar{b}_{i} \bar{b}_{j}\left[g_{i j}(r)-1\right] .
$$

\subsection{X-ray diffraction}

The x-ray diffraction experiments were conducted using a diffractometer (PANalytical X'Pert PRO) operating with a Mo $\mathrm{K} \alpha$ radiation $(\lambda=0.7093 \AA)$. Intensities were measured in the angular range $2^{\circ}<2 \theta<148^{\circ}$, which corresponds to the $Q$ range $0.3 \AA^{-1}<2 \theta<17 \AA^{-1}$. Data were corrected for polarization and absorption, Compton scattering and normalized using the Krogh-Moe-Norman method to obtain the weighted structure factor $F^{\mathrm{X}}(Q)$ [27]. For x-ray diffraction, the weighted total structure factor of the studied glass is defined as

$$
\begin{aligned}
& F^{\mathrm{X}}(Q)=\sum_{i, j} c_{i} c_{j} f_{i}(Q) f_{j}(Q) \\
& \quad \times\left[F_{i j}(Q)-1\right] /\left(\sum_{i} c_{i} f_{i}(Q)\right)^{2},
\end{aligned}
$$

where $f_{i}(Q)$ represents the $Q$-dependent x-ray scattering factor for species $i$.

The Fourier transform is obtained as in equation (2) using an exponential function, $\exp \left(-\alpha Q^{2}\right)$, with $\alpha=0.005$ as the modification function, which gives the differential correlation function $D^{\mathrm{X}}(r)$ for X-ray diffraction data.

\section{4. ${ }^{27}$ Al high-resolution solid-state nuclear magnetic resonance}

The ${ }^{27} \mathrm{Al}$ high-resolution NMR experiments have been conducted at $17.6 \mathrm{~T}(750 \mathrm{MHz})$ on a Bruker AVANCE spectrometer equipped with a high-speed MAS probehead (spinning rates $30 \mathrm{kHz}$, aluminum-free zirconia rotors of $2.5 \mathrm{~mm}$ diameter). 1D MAS spectra were acquired using a single short pulse $(p / 10)$ to ensure a quantitative excitation and quantification of the ${ }^{27} \mathrm{Al}$ central transition [28]. The 2D multiple quanta magic-angle spinning (MQ-MAS) experiments [29] were acquired using the shifted-echo pulse sequence with acquisition and processing of the full echo [30] and synchronized acquisition of the indirect dimension [31]. Chemical shifts were referenced relative to an $\mathrm{Al}\left(\mathrm{NO}_{3}\right)_{3} 1 \mathrm{M}$ solution. As the $\mathrm{T} 1$ relaxation time of each species was estimated at a few hundred milliseconds, a $1 \mathrm{~s}$ recycling delay was used to ensure that the one-pulse MAS spectra was quantitative. 


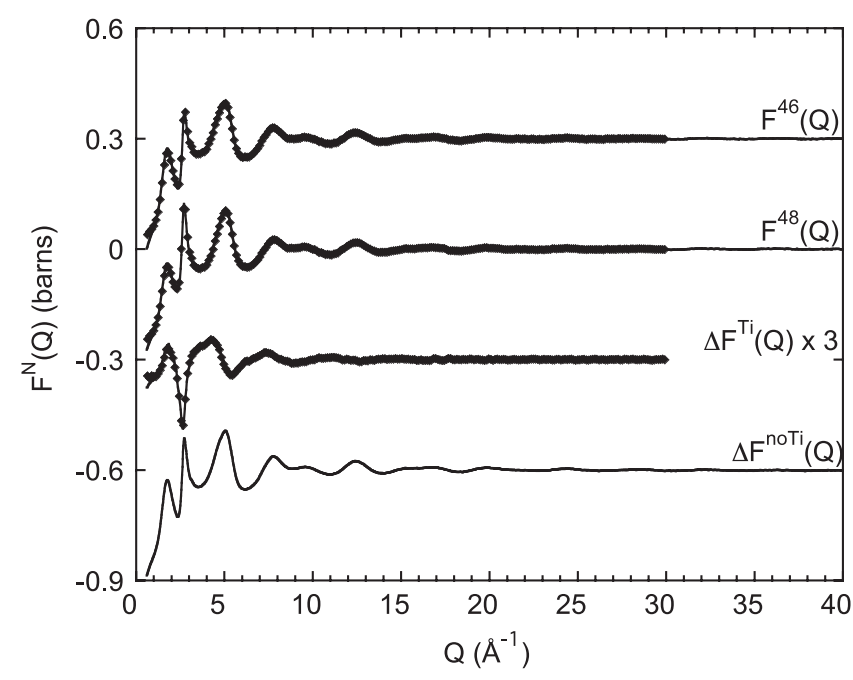

Figure 1. Structure factors obtained from neutron diffraction (solid line) and RMC modeling (filled square) for the ${ }^{46} \mathrm{Ti}$-enriched and ${ }^{48} \mathrm{Ti}$-enriched glasses, for the first difference structure factor $\Delta F^{\mathrm{Ti}}(Q)$ and the second difference structure factor $\Delta F^{\mathrm{noTi}}(Q)$. Curves have been displaced vertically for clarity.

\section{Results}

\subsection{Neutron diffraction data}

The neutron scattering structure factors for the two glasses containing titanium and for the difference structure factors, $\Delta F^{\mathrm{Ti}}(Q)$ and $\Delta F^{\mathrm{noTi}}(Q)$, are plotted in figure 1. A first peak occurs at $Q_{\mathrm{p}}=1.75 \pm 0.02 \AA^{-1}$, whose intensity is slightly higher in the $F^{46}(Q)$ function compared to the $F^{48}(Q)$ one. This peak implies a structural arrangement beyond the first coordination shell and corresponds to density fluctuations over a repeat distance $2 \pi / Q_{\mathrm{p}} \approx 3.59 \AA$. It appears in both the $\Delta F^{\mathrm{Ti}}(Q)$ and $\Delta F^{\mathrm{noTi}}(Q)$ functions, indicating that it is also associated with the organization of both $\mathrm{Ti}$ atoms and the alumino-silicate network.

The differential correlation functions for the two glasses $D^{46}(r)$ and $D^{48}(r)$, the Ti-centered difference correlation $\Delta D^{\mathrm{Ti}}(r)$ and the 'Ti-free' difference function $\Delta D^{\mathrm{noTi}}(r)$ are shown in figure 2. In the $D^{46}(r)$ and $D^{48}(r)$ functions, a first peak at $1.63 \AA$ encompasses both $\mathrm{Si}-\mathrm{O}$ and $\mathrm{Al}-\mathrm{O}$ correlations. Changes in intensity between 1.7 and $2.1 \AA$ are due to Ti-O correlations and correspond to a strong peak in the differential $\Delta D^{\mathrm{Ti}}(r)$ function. Around $2 \AA$ in the $D^{N}(r)$ functions, $\mathrm{Mg}-\mathrm{O}$ correlations are also expected [32]. The intense peak at $2.66 \AA$ is mainly due to O-O correlations, as is the peak at $5.1 \AA$. The peak at $4.1 \AA$ is due mainly to correlations between ( $\mathrm{Si}$, $\mathrm{Al})$ and $\mathrm{O}$ second neighbors. The first peak of the $\Delta D^{\mathrm{Ti}}(r)$ function occurs at $\sim 1.86 \AA$ and corresponds to Ti-O distances. This peak is well separated from other contributions and is asymmetric at high $r$ values.

The experimental mean coordination number around $\mathrm{Ti}$, $C N_{\mathrm{Ti}}$, is determined using two distinct methods. First we calculated $C N_{\mathrm{Ti}}$ from the Ti-O PPDF $g_{\mathrm{TiO}}$ using the formula

$$
C N_{\mathrm{Ti}}=\int_{r_{1}}^{r_{2}} 4 \pi r^{2} \rho_{0} c_{\mathrm{O}} g_{\mathrm{TiO}}(r) \mathrm{d} r
$$

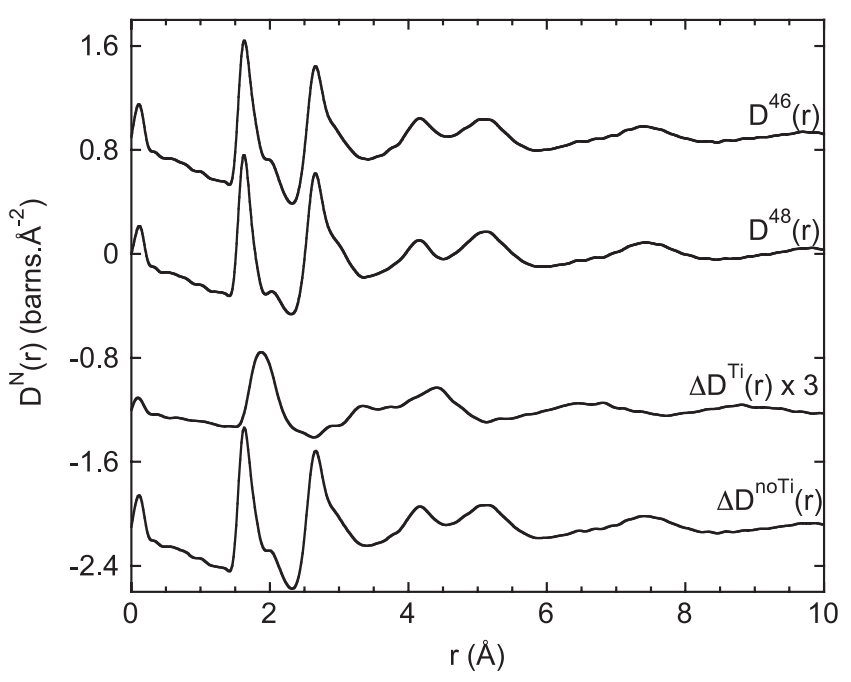

Figure 2. Differential correlation functions obtained from neutron diffraction for the ${ }^{46}$ Ti-enriched glass, $D^{46}(r)$, and for the ${ }^{48}$ Ti-enriched glass, $D^{48}(r)$, both calculated by Fourier transform of the structure factors shown in figure 1 over the interval $0.6-40 \AA^{-1}$. Ti-centered correlation function, $\Delta D^{\mathrm{Ti}}(r)$ (Fourier transform interval 0.6-28 $\AA^{-1}$ ), and 'Ti-free' correlation function, $\Delta D^{\text {noTi }}(r)$ (Fourier transform interval $0.6-40 \AA^{-1}$ ). Curves have been displaced vertically for clarity.

$g_{\mathrm{TiO}}(r)$ is calculated from the $\Delta D^{\mathrm{Ti}}(r)$ function by assuming that, for distances below $2.6 \AA$, titanium atoms are correlated to oxygen atoms only, i.e. only the Ti-O PPDF is present (all other PPDFs involving titanium are null), which gives

$$
\begin{aligned}
& \underset{r<2.6 \AA}{\Delta D^{\mathrm{Ti}}(r)}=4 \pi r \rho_{0} c_{\mathrm{Ti}}\left(\bar{b}_{46}-\bar{b}_{48}\right)\left[2 c_{\mathrm{O}} \bar{b}_{\mathrm{O}}\left(g_{\mathrm{TiO}}-1\right)\right. \\
& \left.\quad-c_{\mathrm{Ti}}\left(\bar{b}_{46}+\bar{b}_{48}\right)-\sum_{i \neq \mathrm{Ti}} 2 c_{i} \bar{b}_{i}\right] .
\end{aligned}
$$

Consequently $g_{\mathrm{TiO}}(r)$ is expressed as

$$
\begin{aligned}
& \underset{r<2.6 \AA}{g_{\mathrm{TiO}}}(r)=\left[\frac{\Delta D^{\mathrm{Ti}}(r)}{4 \pi r \rho_{\mathrm{O}} c_{\mathrm{Ti}}\left(\bar{b}_{46}-\bar{b}_{48}\right)}+c_{\mathrm{Ti}}\left(\bar{b}_{46}+\bar{b}_{48}\right)\right. \\
& \left.\quad+\sum_{i \neq \mathrm{Ti}} 2 c_{i} \bar{b}_{i}\right] \frac{1}{2 c_{\mathrm{O}} \bar{b}_{\mathrm{O}}} .
\end{aligned}
$$

Using equation (10), $C N_{\mathrm{Ti}}$ is assessed between 1.6 and $2.5 \AA$, giving a value of $5.4 \pm 0.2$.

The second method to determine $C N_{\mathrm{Ti}}$ was from a Gaussian fit of the first peak of the $\Delta D^{\mathrm{Ti}}(r)$ function, with the Gaussian function expressed as

$$
\operatorname{Gauss}(r)=\frac{c_{\mathrm{Ti}} b_{i} b_{\mathrm{Ti}} C N_{\mathrm{Ti}}}{r \sqrt{2 \pi \sigma_{i}^{2}}} \exp \left(-\frac{\left(r-R_{i}\right)^{2}}{2 \sigma_{i}^{2}}\right) .
$$

The values $C N_{\mathrm{Ti}}, R_{i}$ (interatomic distance) and $s_{i}$ (standard deviation) are adjustable parameters. To account for the truncation effects in the Fourier transform, the Gaussian function is convoluted with $P(r)$, the Fourier transform of the modification function:

$$
D(r)=\int_{-\infty}^{\infty} \operatorname{Gauss}(t) P(r-t) \mathrm{d} t
$$




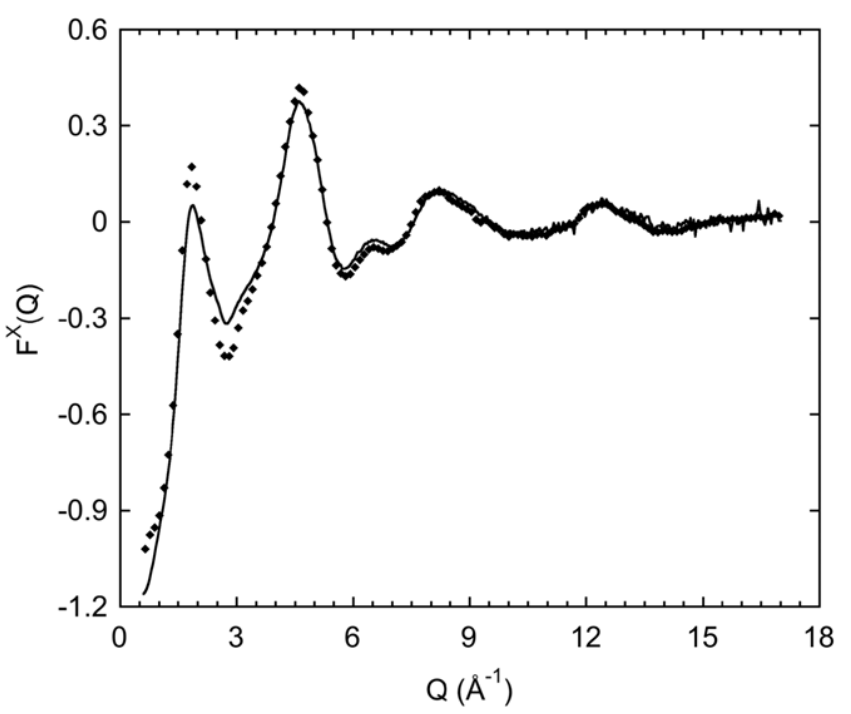

Figure 3. Structure factors obtained from $x$-ray diffraction (solid line) and from the RMC modeling (filled square) for the $2 \mathrm{MgO}-2 \mathrm{Al}_{2} \mathrm{O}_{3}-5 \mathrm{SiO}_{2}-\mathrm{TiO}_{2}$ (Ti-COR) glass.

with

$$
P(r)=\int_{0}^{Q_{\max }} \frac{1}{\pi} \frac{\sin \left(\pi Q / Q_{\max }\right)}{\pi Q / Q_{\max }} \cos (Q r) \mathrm{d} Q
$$

if the modification function is a Lorch function, or

$$
P(r)=\frac{\sin \left(Q_{\max } r\right)}{\pi r}
$$

if the modification function is a step function. Due to the asymmetry of the peak around $2 \AA$ in $\Delta D^{\mathrm{Ti}}(r)$, three Gaussian functions were used, giving a $C N_{\mathrm{Ti}}$ value of $5.45 \pm 0.2$.

Both methods thus give excellent agreement. It should be noted that the assignment of a Gaussian peak to a single $\mathrm{Ti}$ site (four-, five- or sixfold) is unsuccessful, probably due to the strong overlapping of these contributions, as can be seen in many crystalline references. The difference in the $\mathrm{Mg}-\mathrm{O}$ content between the ${ }^{48} \mathrm{Ti}$-and ${ }^{46} \mathrm{Ti}$-enriched glasses can also lead to a residual $\mathrm{Mg}-\mathrm{O}$ contribution whose effect is difficult to estimate.

Between 2.6 and $5 \AA$, contributions can be observed at 3.34 and $4.40 \AA$ in $\Delta D^{\mathrm{Ti}}(r)$. Due to the weight of the difference PPDFs, the peak at $3.34 \AA$ is likely associated with $\mathrm{Ti}-\mathrm{Si}$ (and Ti-Al) contributions. Ti-Ti distances can be expected in this region but the weight of this pair is $10 \%$ that of the Ti-Si pair and it should appear as a negative contribution since this pair is weighted by $\left(c_{\mathrm{Ti}}^{2} \bar{b}_{46}^{2}-c_{\mathrm{Ti}}^{2} \bar{b}_{48}^{2}\right)$ with $\left|\bar{b}_{46}\right|<$ $\left|\bar{b}_{48}\right|$. The peak at $4.40 \AA$ can be ascribed to correlations between $\mathrm{Ti}$ and $\mathrm{O}$ second neighbors. Beyond this distance, broad oscillations are discernible up to $12 \AA$ and correspond to the overlapping of the various Ti-centered PPDFs.

The 'Ti-free' correlation function $\Delta D^{\mathrm{noTi}}(r)$ is very similar to the correlation functions $D^{46}(r)$ and $D^{48}(r)$. This is related to the small amount of titanium atoms in the Ti-bearing glass, which represents only $3.2 \%$ of the total number of atoms and gives a weak contribution.
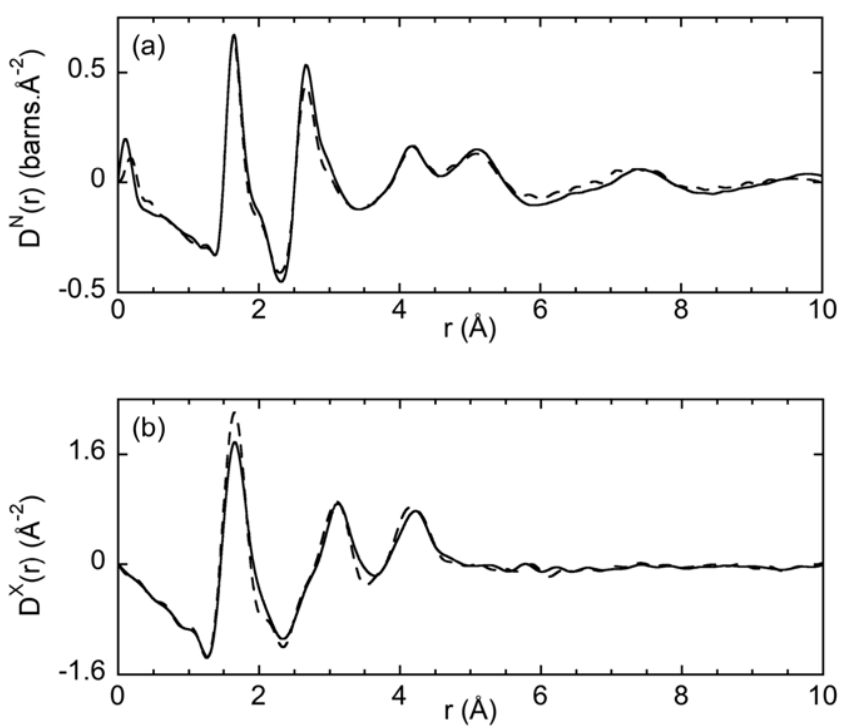

Figure 4. Differential correlation functions for the $2 \mathrm{MgO}-2 \mathrm{Al}_{2} \mathrm{O}_{3}-5 \mathrm{SiO}_{2}$ (COR) glass (dashed line) and for the $2 \mathrm{MgO}-2 \mathrm{Al}_{2} \mathrm{O}_{3}-5 \mathrm{SiO}_{2}-\mathrm{TiO}_{2}$ ( $\mathrm{Ti}-\mathrm{COR}$ ) glass (solid line) obtained (a) from neutron diffraction (Fourier transform interval $0.8-30 \AA^{-1}$ ) and (b) from x-ray diffraction (Fourier transform interval 0.6-17 $\AA^{-1}$ ).

\subsection{X-ray diffraction data}

Compared to neutron diffraction, which is mainly sensitive to correlations involving oxygen, $\mathrm{x}$-ray diffraction gives a strong weight to correlations involving heavy atoms such as titanium. The x-ray structure factor for the Ti-COR glass, $F^{\mathrm{X}}(Q)$, is plotted in figure 3 and its correlation function, $D^{\mathrm{X}}(r)$, is plotted in figure 4. As the range of momentum transfer $Q$ is narrower for x-ray diffraction than for neutron diffraction, the $D^{\mathrm{X}}(r)$ function is less resolved in real space than the neutron correlation functions. The first peak appears between 1.3 and $2.4 \AA$ with a shoulder at high $r$ values. It corresponds to $\mathrm{Si}-$ $\mathrm{O}, \mathrm{Al}-\mathrm{O}, \mathrm{Ti}-\mathrm{O}$ and $\mathrm{Mg}-\mathrm{O}$ correlations. Compared to neutron diffraction data, the strong $\mathrm{O}-\mathrm{O}$ peak at $2.6 \AA$ is now a shoulder while the peak at $3.1 \AA$ is dominant in the x-ray diffraction data. This latter peak can be ascribed mainly to T-T correlations with $\mathrm{T}=\mathrm{Si}$, Al since the Ti-Ti contribution is expected at higher distances (see below).

\subsection{Aluminum environment: ${ }^{27} \mathrm{Al}$ NMR data}

${ }^{27}$ Al NMR MAS and MQ-MAS spectra of COR and Ti-COR samples are shown in figure 5. They were deconvoluted using the DMfit Software [33] and the NMR parameters obtained for each site are reported in table 2 . In both cases, we can distinguish three types of environment for the aluminum atoms: fourfold-, ${ }^{[4]} \mathrm{Al}$, fivefold-, ${ }^{[5]} \mathrm{Al}$, and sixfold-, ${ }^{[6]} \mathrm{Al}$, coordinated aluminum atoms. In alumino-silicate glasses, aluminum atoms are substituted for silicon atoms in tetrahedral sites when associated with some 'charge balancing' cations, such as sodium, magnesium or calcium ions [34]. In the COR glass, enough $\mathrm{Mg}^{2+}$ ions are present to charge-compensate the negative charge of the aluminate tetrahedra and, looking only to the glass composition, all aluminum atoms are expected to be ${ }^{[4]} \mathrm{Al}$. However, it appears that significant amounts of ${ }^{[5]} \mathrm{Al}$ 

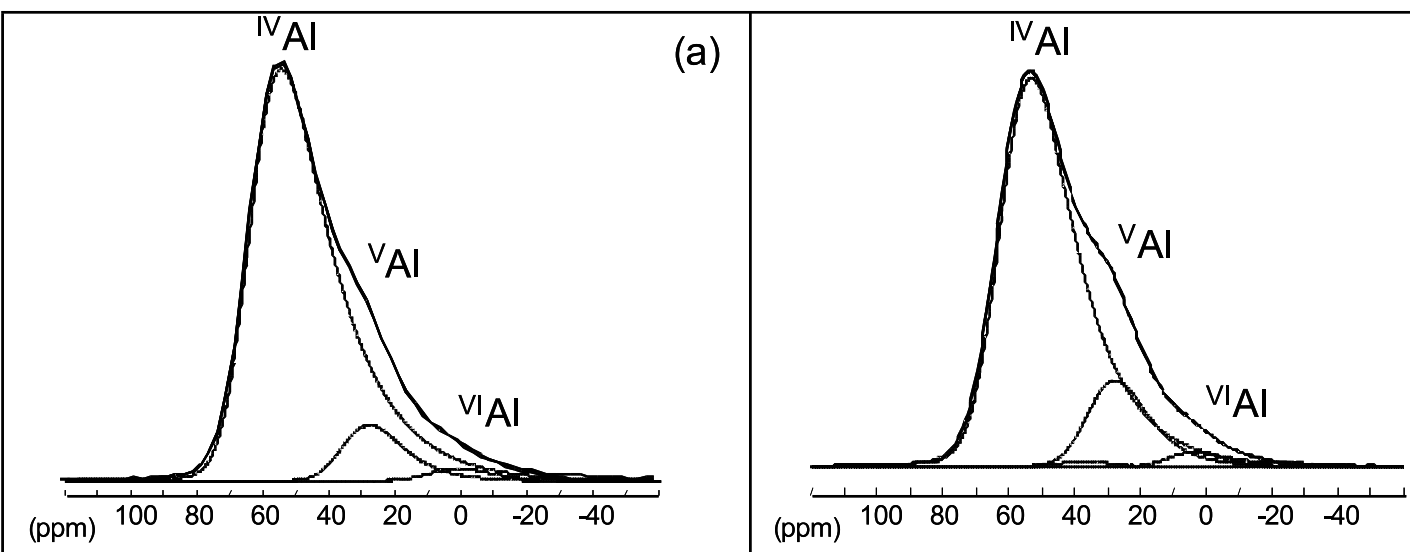

(b)
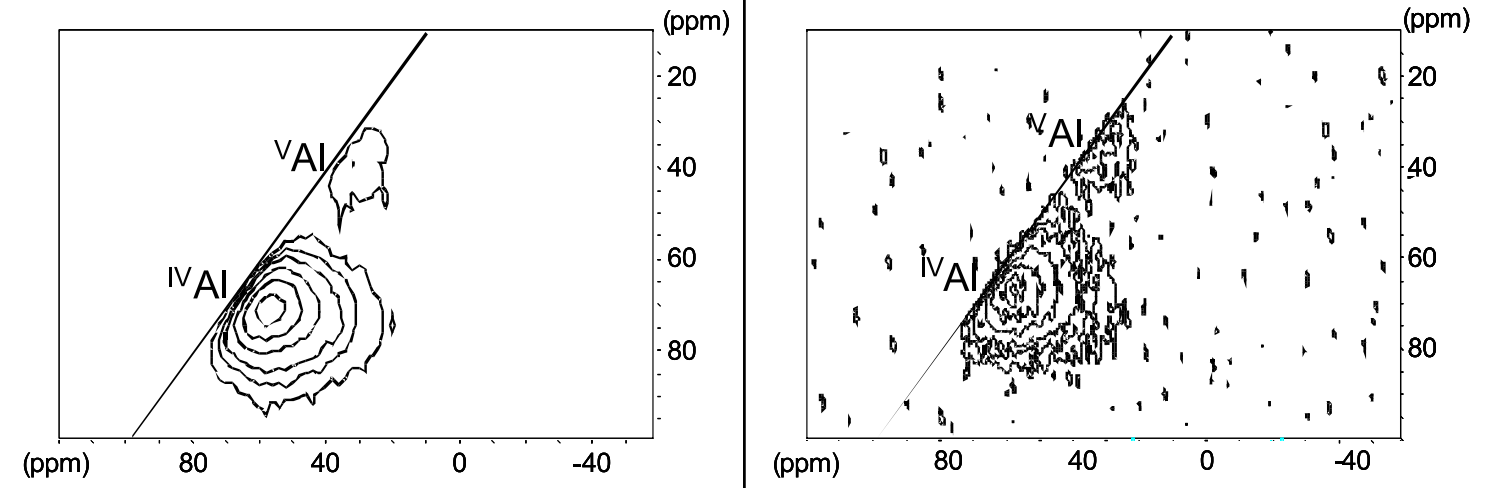

Figure 5. ${ }^{27} \mathrm{Al}$ 1D NMR experimental spectra and the fitting models obtained with parameters given in table 2 (top) and contour plots of ${ }^{27} \mathrm{Al}$ MQ-MAS NMR spectra (bottom) for the (a) $2 \mathrm{MgO}-2 \mathrm{Al}_{2} \mathrm{O}_{3}-5 \mathrm{SiO}_{2}$ (COR) glass and for the (b) $2 \mathrm{MgO}-2 \mathrm{Al}_{2} \mathrm{O}_{3}-5 \mathrm{SiO}_{2}-\mathrm{TiO}_{2}$ ( $\mathrm{Ti}-\mathrm{COR}$ ) glass

Table 2. ${ }^{27} \mathrm{Al}$ NMR parameters (isotropic chemical shift $\delta_{\text {iso }}$ and quadrupolar coupling constant $C_{\mathrm{Q}}$ ) and aluminum coordination distribution for the $2 \mathrm{MgO}-2 \mathrm{Al}_{2} \mathrm{O}_{3}-5 \mathrm{SiO}_{2}\left(\mathrm{COR}\right.$ ) and $2 \mathrm{MgO}-2 \mathrm{Al}_{2} \mathrm{O}_{3}-5 \mathrm{SiO}_{2}-\mathrm{TiO}_{2}$ (Ti-COR) glasses.

\begin{tabular}{llcc}
\hline & & $2 \mathrm{MgO}-2 \mathrm{Al}_{2} \mathrm{O}_{3}-5 \mathrm{SiO}_{2}$ & $2 \mathrm{MgO}-2 \mathrm{Al}_{2} \mathrm{O}_{3}-5 \mathrm{SiO}_{2}-\mathrm{TiO}_{2}$ \\
\hline${ }^{[4]} \mathrm{Al}$ & $\delta_{\text {iso }}(\mathrm{ppm})$ & 64.5 & 63.6 \\
& $C_{\mathrm{Q}}(\mathrm{MHz})$ & 9.2 & 8.5 \\
& $\%$ & 89.1 & 83.3 \\
${ }^{[5]} \mathrm{Al}$ & $\delta_{\text {iso }}(\mathrm{ppm})$ & 35.4 & 34.3 \\
& $C_{\mathrm{Q}}(\mathrm{MHz})$ & 7.2 & 7.0 \\
& $\%$ & 8.9 & 14.6 \\
${ }^{[6]} \mathrm{Al}$ & $\delta_{\text {iso }}(\mathrm{ppm})$ & 8.0 & 10.0 \\
& $C_{\mathrm{Q}}(\mathrm{MHz})$ & 6.67 & 6.1 \\
& $\%$ & 2.1 & 2.1 \\
\hline
\end{tabular}

and ${ }^{[6]} \mathrm{Al}$ exist in this glass, as is observed in other $\mathrm{Ca}-$ aluminosilicate glasses [35] and Mg-alumino-silicate glasses [36, 37]. When introducing titanium in the melts, we observe a slight increase of the chemical shift $\left(\delta_{\text {iso }}\right)$ and of the quadrupolar coupling constant $\left(C_{\mathrm{Q}}\right)$ of each site that can be correlated to an increased distortion of the $\mathrm{Al}$ environment. More interesting, the total amount of ${ }^{[5]} \mathrm{Al}$ and ${ }^{[6]} \mathrm{Al}$ increases from 11 to $17 \%$ with the addition of $\mathrm{TiO}_{2}$. The same trend was observed in other glasses with different $\mathrm{TiO}_{2}$ content (not presented): the higher the $\mathrm{TiO}_{2}$ content the higher the amount of highly coordinated aluminum atoms.

\subsection{Reverse Monte Carlo modeling}

To propose a structural model for the studied glass, reverse Monte Carlo (RMC) modeling [38] was used by combining neutron and $\mathrm{x}$-ray diffraction data and coordination constraints. The starting configurations for the simulation were obtained using molecular dynamics (MD) simulations (DL_POLY code, www.ccp5.ac.uk/DL_POLY/) [39] to provide more reliable models than those obtained by standard RMC modeling [37, 40]. The description of the interaction potential and its parameters were taken from Guillot and Sator [41] and applied to a box of 4160 atoms with the nominal composition. This corresponds to a box size of $37.48 \AA$, in agreement with the experimental density. The interaction potential for the Ti$\mathrm{O}$ pair was adjusted to give a first Ti-O distance centered at $1.86 \AA$. The calculations were performed in the NVT ensemble. The liquid was equilibrated at high temperature $(3000 \mathrm{~K})$ and then quenched to solid state with a cooling rate of $10^{13} \mathrm{~K} \mathrm{~s}^{-1}$. The final configuration obtained by MD was then used as the starting one in the RMC procedure. 
Table 3. Mean nearest-neighbor distance $R_{\mathrm{X}-\mathrm{O}}(\AA)$, coordination number distributions for atom $\mathrm{X}$ and average coordination number $\mathrm{CN}$ for the glass $2 \mathrm{MgO}-2 \mathrm{Al}_{2} \mathrm{O}_{3}-5 \mathrm{SiO}_{2}-\mathrm{TiO}_{2}$ (Ti-COR).

Coordination number distributions were calculated from RMC modeling within a radius of $1.90,2.25,2.5$ and $2.65 \AA$ for $\mathrm{Si}-\mathrm{O}$, $\mathrm{Al}-\mathrm{O}, \mathrm{Ti}-\mathrm{O}$ and $\mathrm{Mg}-\mathrm{O}$ distances, respectively. The experimental coordination numbers for $\mathrm{Al}$ and $\mathrm{Ti}$ are from ${ }^{27} \mathrm{Al} \mathrm{NMR}$ and neutron diffraction with isotopic substitution, respectively.

\begin{tabular}{llcc}
\hline & & RMC modeling & Experimental \\
\hline $\mathrm{Si}-\mathrm{O}$ & $R_{\mathrm{Si}-\mathrm{O}}(\AA)$ & 1.62 & \\
& $\mathrm{CN}$ & 4.00 & \\
$\mathrm{Al}-\mathrm{O}$ & $R_{\mathrm{Al}-\mathrm{O}}(\AA)$ & 1.73 & \\
& ${ }^{[4]} \mathrm{Al}(\%)$ & 92.3 & 83.3 \\
& ${ }^{[5]} \mathrm{Al}(\%)$ & 7.3 & 14.6 \\
& ${ }^{[6]} \mathrm{Al}(\%)$ & 0.4 & 2.1 \\
& $\mathrm{CN}$ & 4.08 & 4.19 \\
$\mathrm{Ti}-\mathrm{O}$ & $R_{\mathrm{Ti}-\mathrm{O}}(\AA)$ & 1.85 & 1.86 \\
& ${ }^{[4]} \mathrm{Ti}(\%)$ & 20.8 & \\
& ${ }^{[5]} \mathrm{Ti}(\%)$ & 51.5 & \\
& ${ }^{[6]} \mathrm{Ti}(\%)$ & 27.7 & \\
& $\mathrm{CN}$ & 5.07 & 5.4 \\
$\mathrm{Mg}-\mathrm{O}$ & $R_{\mathrm{Mg}-\mathrm{O}}(\AA)$ & 2.05 & \\
& ${ }^{[3]} \mathrm{Mg}(\%)$ & 3.1 & \\
& ${ }^{[4]} \mathrm{Mg}(\%)$ & 34.2 & \\
& ${ }^{[5]} \mathrm{Mg}(\%)$ & 48.1 & \\
& ${ }^{[6]} \mathrm{Mg}(\%)$ & 14.6 & \\
& $\mathrm{CN}$ & 4.74 & \\
\hline
\end{tabular}

During the RMC modeling, all silicon atoms were constrained to be coordinated to four oxygen atoms. Aluminum atoms were constrained to be coordinated to four, five or six oxygen atoms with the proportions determined by ${ }^{27} \mathrm{Al}$ NMR. The RMC technique has been previously described [38] and consists of minimizing the squared difference between the experimental and calculated structure factors by moving the atoms randomly. This ultimately gives atomic models in quantitative agreement with experimental data. In the present study, both neutron $\left(F^{46}(Q), F^{48}(Q)\right.$ and $\left.\Delta D^{\mathrm{Ti}}(Q)\right)$ and $\mathrm{x}$ ray diffraction $\left(F^{\mathrm{X}}(Q)\right)$ data were used simultaneously to constrain the RMC fitting. As the signal-to-noise ratio is less in the x-ray diffraction data than those for neutron diffraction, a smaller weighting was used for the constraint on the fit of the $F^{\mathrm{X}}(Q)$. The weights were 0.002 for the neutron diffraction data, 0.01 for the $\mathrm{x}$-ray diffraction data, 0.001 to maintain $\mathrm{SiO}_{4}$ coordination and 0.002 to fit the $\mathrm{Al}$ coordination to the NMR results.

Experimental structure factors and their RMC fits are compared in figures 1 and 3 , showing the good quality of the fit. Coordination numbers $(\mathrm{CN})$ were calculated from RMC modeling within a radius of $1.90,2.25$ and $2.80 \AA$ for $\mathrm{Si}-\mathrm{O}, \mathrm{Al}-\mathrm{O}$ and $\mathrm{Mg}-\mathrm{O}$ distances, respectively, corresponding to the first minimum in the PPDFs. Results are shown in table 3. As expected, all silicon atoms are coordinated by four oxygen atoms. Aluminum and titanium atoms present multiple coordination numbers and they can be coordinated by four, five or six oxygen atoms, with an average number around 4.08 for $\mathrm{Al}$ and 5.07 for $\mathrm{Ti}$. The proportion in $\mathrm{Al}$ sites determined with RMC does not perfectly match the NMR results since small moves have been allowed $(0.02 \AA)$ to avoid unphysical distortion of the polyhedra. It must also be noted that this coordination strongly depends on the cutoff distance and an Al-O cutoff of $2.55 \AA$ is needed to agree with the NMR results. Furthermore, the network connectivity is high, which limits important reorganization of the network compared to the initial MD model. The environment of magnesium atoms is distributed with four possible coordination numbers, from three to six, including four and five, and an average coordination number of 4.74 .

\section{Discussion}

\subsection{Effect of the introduction of titanium dioxide on the glass structure}

The differential correlation functions for the COR glass and for the Ti-COR glass are compared in figure 4 for neutron (figure 4(a)) and x-ray diffraction (figure 4(b)). The experimental data and RMC modeling for the COR glass were presented in a previous paper [37]. The addition of $11.1 \mathrm{~mol} \%$ $\mathrm{TiO}_{2}$ does not significantly modify the structure. The first peak at $1.65 \AA$ is almost unchanged in the $D^{N}(r)$ functions that are more sensitive to $\mathrm{Si}-\mathrm{O}$ and $\mathrm{Al}-\mathrm{O}$ correlations, except for a broadening at high $r$ value. In the $D^{\mathrm{X}}(r)$ functions, this peak becomes wider, less intense and with a contribution at high $r$ value as $\mathrm{TiO}_{2}$ is introduced. The broadening can be correlated to the increase of quadrupolar coupling constants characteristic of aluminum environments and to the increasing amount of highly coordinated $\mathrm{Al}$ in $\mathrm{Ti}-\mathrm{COR}$, as shown by ${ }^{27} \mathrm{Al} \mathrm{NMR}$ experiments. Indeed, longer $\mathrm{Al}-\mathrm{O}$ distances are expected than for tetrahedrally coordinated Al. The shoulder at high $r$ value is clearly due to the contribution of the titanium-oxygen correlation around 2.0 $\AA$. The $D^{\mathrm{X}}(r)$ function of the TiCOR glass shows the appearance of a new contribution around $3.45 \AA$. This peak corresponds to correlations between two cations, one of which is a titanium atom. Finally, we observe a shift toward longer distances of the third peak occurring around $4.5 \AA$, which corresponds to the second mean cation-oxygen distance.

${ }^{27} \mathrm{Al}$ NMR results show a modification of the aluminosilicate network with the formation of highly coordinated aluminum atoms, mainly ${ }^{[5]} \mathrm{Al}$, as $\mathrm{TiO}_{2}$ is introduced. The presence of highly coordinated aluminum atoms is well established in alkaline-earth alumino-silicate glasses because alkaline-earth cations are less good charge compensators than alkalis [35-37]. However, quantitative evaluation of these species gives lower ${ }^{[5]} \mathrm{Al}$ and ${ }^{[6]} \mathrm{Al}$ content for the $\mathrm{COR}$ glass than for the Ti-COR glass. In the presence of $\mathrm{TiO}_{2}$, titanium atoms can compete favorably with aluminum atoms for charge compensation. Different studies tried to establish a correlation between the presence and amount of highly coordinated aluminum species and the variation of viscosity or glass transition temperatures [35, 42]. It seems that the presence of ${ }^{[5]} \mathrm{Al}$ species in melts can often be associated with a low viscosity. In our case, the formation of these $\mathrm{Al}$ species can partly explain the decrease of the glass transition temperature observed with increasing titanium content [43]. The presence of ${ }^{[5]} \mathrm{Al}$ species should also contribute to the distortion and weakening of the network. 


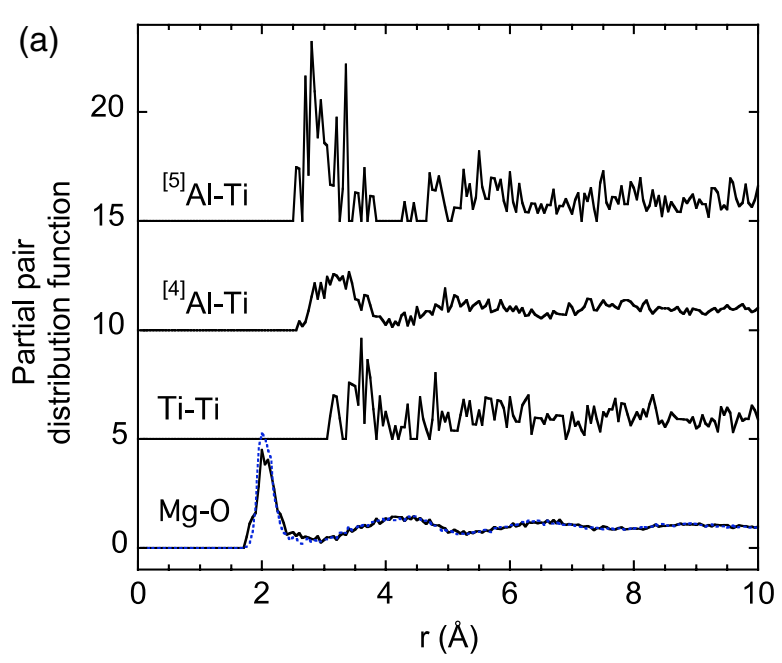

(b)

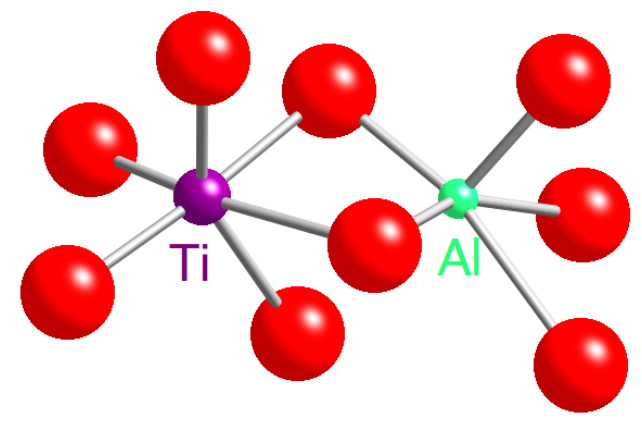

Figure 6. (a) Partial pair distribution function obtained from the $\mathrm{RMC}$ model for ${ }^{[4]} \mathrm{Al}-\mathrm{Ti}$, ${ }^{[5]} \mathrm{Al}-\mathrm{Ti}$, Ti-Ti and $\mathrm{Mg}-\mathrm{O}$ pairs for the Ti-COR (plain curve) and COR (dashed curve, blue) glasses. (b) Typical bonding observed in the RMC model between a titanium atom (purple) and a ${ }^{[5]} \mathrm{Al}$ atom (green) obtained from the $\mathrm{RMC}$ model of the $2 \mathrm{MgO}-2 \mathrm{Al}_{2} \mathrm{O}_{3}-5 \mathrm{SiO}_{2}-\mathrm{TiO}_{2}$ (Ti-COR) glass. Oxygen atoms are red.

(This figure is in colour only in the electronic version)

The environment of magnesium atoms is slightly modified by the introduction of $\mathrm{TiO}_{2}$. The $\mathrm{Mg}-\mathrm{O}$ PPDF is plotted in figure 6(a) and compared with the Mg-O PPDF obtained for the COR glass [37]. The peak position is similar between the two PPDFs but the full width at half-maximum is slightly wider $(0.3 \AA)$ for the Ti-COR than for the COR glass $(0.28 \AA)$. There are also differences in the mean coordination numbers, with values of 5.10 and 4.74 in the COR [37] and Ti-COR glasses, respectively. This decrease of the coordination number for $\mathrm{Mg}$ atoms when titanium is introduced in the cordierite glass is confirmed by the decrease of the intensity of the peak occurring at $2.05 \AA$ on the 'Tifree' correlation function, $D^{\text {noTi }}(r)$, compared to that on the correlation function for the COR glass. In the Ti-COR glass, a significant amount of $\mathrm{Mg}$ atoms occupy tetrahedral sites. This suggests that $\mathrm{Mg}$ atoms can compete with $\mathrm{Al}$ atoms in network-forming positions. Therefore, they are not available for the charge compensation of $\left(\mathrm{AlO}_{4}\right)^{-}$tetrahedra anymore and $\mathrm{Al}$ atoms are constrained to occupy fivefold-or sixfoldcoordinated sites.

The amount of non-bridging oxygen (NBO) atoms can be calculated from the RMC model. As $\mathrm{Al}$ and $\mathrm{Ti}$ atoms can both be considered either as network formers or as network modifiers, we define an NBO atom as an $\mathrm{O}$ atom bonded only to one $\mathrm{Si}, \mathrm{Al}$ or $\mathrm{Ti}$ atom. We find for the RMC model that the number of NBO atoms represents about $7 \%$ of the total number of oxygen atoms. The model also shows that these NBO atoms tend to be connected to silicon atoms rather than aluminum or titanium atoms. Such an affinity for NBO to be linked with Si atoms has already been determined in calcium alumino-silicate glasses [44]. Recent studies have shown that the presence of NBO for such composition results from the presence of highly coordinated Al that are favored in the liquid state [35, 42]. In the present case highly coordinated $\mathrm{Ti}$ species also promote the formation of NBO.

\subsection{Short-range order around titanium atoms}

The mean Ti-O distance of $1.86 \AA$ (table 3 ) is consistent with previous measurements by EXAFS in alumino-silicate glasses [9] and the asymmetry of the first Ti-O peak comes from the presence of several coordination numbers for Ti atoms with different sets of Ti-O distances. This is proven by the requirement to use several Gaussian functions to fit the first Ti$\mathrm{O}$ peak and confirmed by the RMC fit. This shows that titanium atoms are present with different coordination numbers varying from four to six, including five.

${ }^{[5]} \mathrm{Ti}$ species in amorphous materials occupy either a square-based pyramidal $[9,15,16]$ or a trigonal bipyramidal [8] environment. In our glass, the existence of a $\mathrm{TiO}_{5}$ square-based pyramid cannot be unambiguously ascribed. Gaussian fits (not shown) using either a square-based pyramid or a trigonal bipyramid give similar agreement.

Two independent ways of determining the coordination number are explained in section 3.1. They both give a coordination number for titanium atoms of 5.45 oxygen neighbors. This is also in good agreement with the RMC results, giving a value of 5.07. In the RMC model the coordination distribution can be resolved, giving $21 \%$ of total titanium atoms in fourfold coordination, $51 \%$ in fivefold coordination and $28 \%$ in sixfold coordination. All methods used to determine the coordination number distribution for $\mathrm{Ti}$ atoms agree on the predominance of ${ }^{[5]} \mathrm{Ti}$, with the coexistence of ${ }^{[4]} \mathrm{Ti}$ and ${ }^{[6]} \mathrm{Ti}$ in similar amounts. This is an important difference with other alkaline or alkaline-earth silicate glasses (see [4-19]) that usually present a strong preference for ${ }^{[5]} \mathrm{Ti}$ with minor amounts of ${ }^{[4]} \mathrm{Ti}$. This corresponds to several structural positions for titanium atoms within the glass structure, network former or either network modifier.

\subsection{Medium-range order around titanium atoms}

Comparing the correlation functions for both the COR glass and the Ti-COR glass obtained from x-ray diffraction, a 
widening of the second peak occurring at $3.1 \AA$ is observed and a small shoulder appears at approximately $3.45 \AA$. This shoulder results from the correlations between the titanium atoms and the other cations ( $\mathrm{Si}, \mathrm{Al}, \mathrm{Mg}, \mathrm{Ti}$ ). As the sensitivity of x-ray diffraction to a specific atom increases as its atomic number increases, the method particularly highlights Ti-Ti correlations and we can suggest that the nearest Ti-Ti distance occurs at approximately $3.45 \AA$. The Ti-Ti PPDF obtained from the RMC modeling (figure 6(a)) is noisy due to the low $\mathrm{Ti}$ atomic concentration and the small constraints on this pair in the diffraction functions. The Ti-Ti distance shows that Ti polyhedra tend to be linked by corner sharing rather than by edge sharing, which will lead to shorter Ti-Ti distances. This means that $\mathrm{Ti}$ atoms are not closely packed, as they usually are in crystalline $\mathrm{TiO}_{2}$ polymorphs (rutile, anatase and brookite) [45]. Therefore, considering both the correlation function for the Ti-bearing glass obtained from $\mathrm{x}$ ray diffraction and the RMC model, we do not see evidence for the aggregation of $\mathrm{Ti}$ atoms into Ti-rich areas in the TiCOR glass. This phase separation between a Ti-rich zone and an Si-rich zone is usually believed to be responsible for the homogeneous crystallization of Ti-bearing alumino-silicate glasses [2, 46].

The RMC modeling of the COR glass indicates that the highly coordinated aluminum atoms tend to aggregate to form clusters of a few $\mathrm{AlO}_{5}$ entities [37]. The same trend is also observed in the Ti-COR glass. Furthermore, the model shows that the distance between these highly coordinated $\mathrm{Al}$ atoms and $\mathrm{Ti}$ atoms is shorter $(2.9 \AA)$ than that measured between

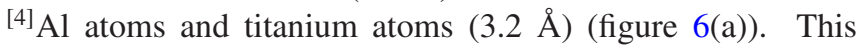
indicates that highly coordinated aluminum atoms tend to share edges with $\mathrm{Ti}$ polyhedra (figure $6(\mathrm{~b})$ ) while ${ }^{[4]} \mathrm{Al}$ are linked with Ti polyhedra by corner sharing. This result has important implications for understanding nucleation of alumino-silicate glasses. Indeed, crystals in the $\mathrm{MgTi}_{2} \mathrm{O}_{5}-\mathrm{Al}_{2} \mathrm{TiO}_{5}$ solid solution usually precipitate during the nucleation of Tibearing magnesium alumino-silicate glasses [46]. These phases are built from edge-shared $\mathrm{MgO}_{6}, \mathrm{AlO}_{6}$ and $\mathrm{TiO}_{6}$ octahedra $[47,48]$. Therefore, this preferential edge-sharing bond shown in figure $6(\mathrm{~b})$ between highly coordinated $\mathrm{Al}$ atoms and $\mathrm{Ti}$ atoms can act as the seeds for the formation of nuclei in alumino-silicate glasses, especially, since highly coordinated $\mathrm{Al}$ atoms represent one-sixth of the total amount of $\mathrm{Al}$ atoms in the glass.

\section{Conclusions}

The environment of titanium atoms was investigated in a magnesium alumino-silicate glass using neutron diffraction with isotopic substitution, combined with x-ray diffraction and reverse Monte Carlo (RMC) modeling. In the $2 \mathrm{MgO}-$ $2 \mathrm{Al}_{2} \mathrm{O}_{3}-5 \mathrm{SiO}_{2}-\mathrm{TiO}_{2}$ glass, titanium atoms have an average coordination number of $5.4 \pm 0.2$ and they are surrounded by four, five or six oxygen atoms. The fivefold coordination predominates but there is no experimental evidence to distinguish between a square-based pyramid or a trigonal bipyramid. The introduction of titanium dioxide in this magnesium alumino-silicate glass mainly affects the amount of five- and sixfold-coordinated aluminum atoms that increases when the titanium content increases. The RMC model shows that these highly coordinated aluminum atoms tend to be located next to the titanium atoms and that the $\mathrm{TiO}_{x}$, with $x=4,5$ or 6 , and $\mathrm{AlO}_{5}$ polyhedra are sharing edges. We propose that this preferential linkage is a structural key to understand the role of titanium dioxide as nucleating agent in inorganic glass-ceramics fabrication.

\section{Acknowledgments}

We thank Bertrand Guillot for fruitful discussions on the use of DL-Poly code. We would like also to thank the funding support by the French National Research Agency (ANR) under contract no. 06-JCJC-0010 'Nuclevitro'.

\section{References}

[1] Fokin V M, Zanotto E D, Yuritsyn N S and Schmelzer J W P 2006 J. Non-Cryst. Solids 3522681

[2] McMillan P W 1964 Glass-Ceramics (London: Academic)

[3] Sandstrom D R, Lytle F W, Wei P S P, Greegor R B, Wong J and Schultz P 1980 J. Non-Cryst. Solids 41201

[4] Greegor R B, Lytle F W, Sandstrom D R, Wong J and Schultz P 1983 J. Non-Cryst. Solids 5527

[5] Mountjoy G, Pickup D M, Wallidge G W, Anderson R, Cole J M, Newport R J and Smith M E 1999 Chem. Mater. 111253

[6] Dingwell D B, Paris E, Seifert F, Mottana A and Romano C 1994 Phys. Chem. Miner. 21501

[7] Ponader C W, Boeck H and Dickinson J E 1996 J. Non-Cryst. Solids 20181

[8] Farges F 1996 J. Non-Cryst. Solids 20453

[9] Farges F, Brown G E Jr, Navrotsky A, Gan H and Rehr J J 1996 Geochim. Cosmochim. Acta $\mathbf{6 0} 3039$

[10] Farges F 1997 Am. Mineral. 8236

[11] Farges F 1999 J. Non-Cryst. Solids 24425

[12] Henderson G S, Liu X and Fleet M E 2002 Phys. Chem. Miner. 2932

[13] Henderson G S, Liu X and Fleet M E 2003 Miner. Mag. 67597

[14] Romano C, Paris E, Poe B T, Giuli G, Dingwell D B and Mottana A 2000 Am. Mineral. 85108

[15] Yarker C A, Johnson P A V, Wright A C, Wong J, Greegor R B, Lytle F W and Sinclair R N 1986 J. Non-Cryst. Solids 79117

[16] Cormier L, Gaskell P H, Calas G and Soper A K 1998 Phys. Rev. B 5811322

[17] Ramos A, Gandais M and Petiau J 1985 J. Phys. C: Solid State Phys. 8491

[18] Dumas T and Petiau J 1986 J. Non-Cryst. Solids 81201

[19] Brown G E Jr, Farges F and Calas G 1995 Rev. Mineral. Geochem. 32317

[20] Mysen B O 1980 Am. Mineral. 651150

[21] Partridge G 1994 Glass Technol. 35116

[22] Pickup D M, Sowrey F E, Newport R J, Gunawidjaja P N, Drake K O and Smith M E 2004 J. Phys. Chem. B 10810872

[23] Keen D A 2001 J. Appl. Crystallogr. 34172

[24] Majérus O, Cormier L, Calas G and Beuneu B 2003 J. Phys. Chem. B 10713044

[25] Lorch E 1969 J. Phys. C: Solid State Phys. 2229

[26] Cormier L, Calas G and Gaskell P H 2001 Chem. Geol. 174349

[27] Marumo F and Okuno M 1984 Material Science of the Earth's Interior ed I Sunagawa (Tokyo: Terra Scientific) 
[28] Massiot D, Bessada C, Coutures J P and Taulelle F 1990 J. Magn. Reson. 90231

[29] Medek A, Harwood J S and Frydman L 1995 J. Am. Chem. Soc. 11712779

[30] Massiot D, Touzo B, Trumeau D, Coutures J P, Virlet J, Florian P and Grandinetti P J 1996 Solid State Nucl. Magn. Reson. 673

[31] Massiot D 1996 J. Magn. Reson. A 122240

[32] Wilding M C, Benmore C J, Tangeman J A and Sampath S 2004 Chem. Geol. 213281

[33] Massiot D, Fayon F, Capron M, King I, Le Calvé S, Alonso B, Durand J O, Bujoli B, Gan Z and Hoatson G 2002 Magn. Reson. Chem. 4070

[34] Mysen B O and Richet P 2005 Silicate Glasses and Melts: Properties and Structure (Amsterdam: Elsevier)

[35] Neuville D R, Cormier L, Montouillout V and Massiot D 2007 J. Non-Cryst. Solids $\mathbf{3 5 3} 180$

[36] Neuville D R, Cormier L, Montouillout V, Florian P, Millot F, Rifflet J-C and Massiot D 2008 Am. Mineral. 931720
[37] Guignard M and Cormier L 2008 Chem. Geol. 256111

[38] McGreevy R L 2001 J. Phys.: Condens. Matter 13 R877

[39] Smith W and Forester T R 1996 J. Mol. Graphics 14136

[40] Cormier L, Ghaleb D, Delaye J M and Calas G 2000 Phys. Rev. B 6114495

[41] Guillot B and Sator N 2007 Geochim. Cosmochim. Acta 711249

[42] Cormier L, Neuville D R and Calas G 2005 J. Am. Ceram. Soc. 882292

[43] Barry T I, Cox J M and Morrell R 1978 J. Mater. Sci. 13594

[44] Cormier L, Ghaleb D, Neuville D R, Delaye J-M and Calas G 2003 J. Non-Cryst. Solids 332255

[45] Wyckoff R W G 1935 The Structure of Crystals ( American Chemical Society Monograph Series No. 19A) (New York: Reinhold)

[46] Vogel W 1994 Glass Chemistry (New York: Springer)

[47] Yang H and Hazen R M 1998 J. Solid State Chem. 138238

[48] Norberg S T, Ishizawa N, Hoffmann S and Yoshimura M 2005 Acta Crystallogr. E 61 i160 